\title{
2.5D Modelling of Aeromagnetic Data and their Mining Implications over the Ngaoundere Area (Adamawa Province, Cameroon)
}

\author{
Meying Arsène ${ }^{1^{*}}$, Gouet Daniel Hervé2, Ndougsa Mbarga Theophile ${ }^{3,4}$, \\ Ndam Njikam Mouhamed', Owono Amougou Olivier Ulrich Igor ${ }^{3}$ \\ ${ }^{1}$ School of Geology and Mining Engineering, University of Ngaoundere, Meiganga, Cameroon \\ ${ }^{2}$ Department of Petroleum, Mining \& Groundwater Resources Exploration, Faculty of Mines and Petroleum Industries, University \\ of Maroua, Maroua, Cameroun \\ ${ }^{3}$ Department of Physics, Advanced Teacher's Training College, University of Yaoundé I, Yaoundé, Cameroon \\ ${ }^{4}$ Postgraduate School of Science, Technologies \& Geosciences, University of Yaoundé I, Yaoundé, Cameroon \\ Email: *arsenemeying@yahoo.fr
}

How to cite this paper: Arsène, M., Hervé, G.D., Theophile, N.M., Mouhamed, N.N. and Igor, O.A.O.U. (2019) 2.5D Modelling of Aeromagnetic Data and their Mining Implications over the Ngaoundere Area (Adamawa Province, Cameroon). International Journal of Geosciences, 10, 173-192. https://doi.org/10.4236/ijg.2019.102011

Received: December 17, 2018 Accepted: February 17, 2019

Published: February 20, 2019

Copyright $\odot 2019$ by author(s) and Scientific Research Publishing Inc. This work is licensed under the Creative Commons Attribution International License (CC BY 4.0).

http://creativecommons.org/licenses/by/4.0/

\section{(c) (i) Open Access}

\begin{abstract}
This study is based on the analysis and interpretation of aeromagnetic data using version 8.4 of the Geosoft Oasis Montaj Software, to map the subsurface or deep geological structures that affected the geological formations of the Ngaoundere area. The use of the standard aeromagnetic methods made it possible to draw up the maps of the residual magnetic field reduced to the equator (RTE), the horizontal gradient (HG), the analytical signal (AS) and that of the Euler solutions (ED) to find the main magnetic facies corresponding to these structures. The geological formations of the studied area thus appear to be intensely fractured by a NE-SW $\left(\mathrm{N} 45^{\circ} \mathrm{E}\right)$ and ENE-WSW $\left(\mathrm{N} 70^{\circ} \mathrm{E}\right)$ main orientation fault system, the depth of which has been estimated by combining the three-analytical methods HG, AS and ED. Advanced magmatic map analysis revealed dikes associated with vertical faults in the studied area. The development of an interpretative geological map taking into account the basic geology, the deep faults, the identified dikes and the mineralization index made it possible to extract a correlation between geological structures and mineralization of the studied area. The $2.5 \mathrm{D}$ modelling of two magnetic profiles plotted on the reduced residual map at the equator was performed to approximate the geometry and depth of the dikes sector, which are potential sources of mineralization here.
\end{abstract}

\section{Keywords}

Aeromagnetic Data, Analytical Methods, Faults, Mineralization, 2.5D

Modelling 


\section{Introduction}

Since 1970, the Adamawa plateau in general and the studied area has been the subject of several geological studies by several authors, such as the studies conducted by Eno Belinga [1], Dumont [2], Ngounouno [3], roughly covering petrography, geochemistry and tectonics in the study area. The results of these studies show that, on one hand, the basement of the studied area consisted mainly of gneiss and granite, the latter being crossed by granitoids and on the other hand, the major structures of the area had WSW-ENE (N70 $\left.{ }^{\circ} \mathrm{E}\right), \mathrm{NE}-\mathrm{SW}\left(\mathrm{N} 45^{\circ} \mathrm{E}\right)$ and NNE-SSW $\left(\mathrm{N} 30^{\circ} \mathrm{E}\right)$ orientations. Nevertheless, all these studies are superficial and do not therefore give sufficient information on the structures of the subsoil of the studied area. In addition to these studies, few geophysical studies, focused on gravimetric studies [4]-[9] were conducted in the Adamawa region. They consisted of processing and interpreting the gravity data acquired during various gravity campaigns carried out in the sixties over the Cameroonian territory. They aimed to provide additional information on the structuration and geodynamic evolution of the Adamawa plateau. The results from these gravimetric investigations show a fairly good correlation with the surface geology and the directions of the major structures identified here remained similar to the previous ones. Although the information obtained so far is already quite interesting, the scale of the data used in these studies (from 1/3,000,000 to $1 / 500,000$ ) does not allow to have a little more detailed knowledge on geology and the mineralization of the study area as required by mineral exploration. Some additional information that could be derived from aeromagnetic data at scales, like the 1:50,000, would allow to have a much more detailed study. Based on the existence of aeromagnetic data coverage over the studied area, which comprises longitudes $12^{\circ} 30^{\prime}-13^{\circ} 30^{\prime} \mathrm{E}$ and latitudes $6^{\circ} 45^{\prime}-7^{\circ} 15^{\prime} \mathrm{N}$, the present study is initiated to enhance the level of structural knowledge.

Aeromagnetic data have very often been used in the mining sector to detect areas of magnetic anomalies that may correspond to mineral concentration. They are currently widely used for geological land reconnaissance, especially in large areas where land or plant cover is important. The magnetic susceptibility technique from airborne data is therefore used to specify geological interpretations at regional scales. In the case of this study, the main objective is to produce a structural mapping from the aeromagnetic data of the studied area to highlight a correlation between the geological structures (faults, geological contacts) and the possible mineralization of the studied zone.

This study will therefore be unique in that research studies in the study area have so far consisted either of studying the general geology or measuring the average thickness of the earth's crust. They therefore did not provide information on the potential sources of near surface anomalies that are generally important for mineral research. All the results that will come from this study will provide a basic document on the very solid study area to base further investigations in mineral research. 


\section{Geologic and Tectonic Setting of Studied Area}

The studied area covers an area of approximately $4647 \mathrm{Km}^{2}$. It is limited by longitudes $12^{\circ} 30^{\prime}-13^{\circ} 30^{\prime}$ East and latitudes $6^{\circ} 45^{\prime}-7^{\circ} 15^{\prime}$ North. It's a plateau area of altitudes between $875 \mathrm{~m}$ and $1325 \mathrm{~m}$.

The Adamawa plateau is largely covered by large basaltic and basalto-andesitic volcanic effusions of essentially Tertiary age, which extend into the middle part of the southern moat [10] [11] [12] [13]. The basement of the study area is composed of granito-gneissic (Figure 1) intersected by granitoids between 652 and 612million years old [3]. According to Lasserre [14], the region of Adamawa was the seat of intense volcanic activity in the Tertiary and Quaternary, favored by a major fracturing-orientated NW-SE and secondary accidents E-W affecting the basement around Ngaoundere. The Pan-African gneiss and granite units are crossed by mylonitic bands, the largest of which, with a general ENE-WSW orientation, marks out the southern edge of the Adamawa. This myloniticb and corresponds to an important zone of sub-vertical faults having played in the Pan-African [15] [16]. The Adamawa represents an axial mass consisting of Precambrian basement, raised during the Upper Cretaceous and Tertiary and in which, the Adamawa plateau is likened to a horst. This asymmetrical horst located in the Mobile Zone of Central Africa, is limited to the north by the Ngaoundere cliff and to the south by the Mbéré-Djérem moat, both oriented $\mathrm{N} 70^{\circ} \mathrm{E}$ (ENE-WSW) corresponding to the general direction of the Plateau [16]. It is located on the route of large-scale mylonitic accidents. After the Pan-African event, the basement was traversed by magmatic comets corresponding to the tertiary magmatic activity of the "Cameroon Line". This alkaline magmatism is reflected on the Adamawa plateau by the establishment of felsic domes, and basaltic flows. According to some authors [3] [18] [19] [20], the basement tectonics having played several times is responsible for its horst and graben structure.

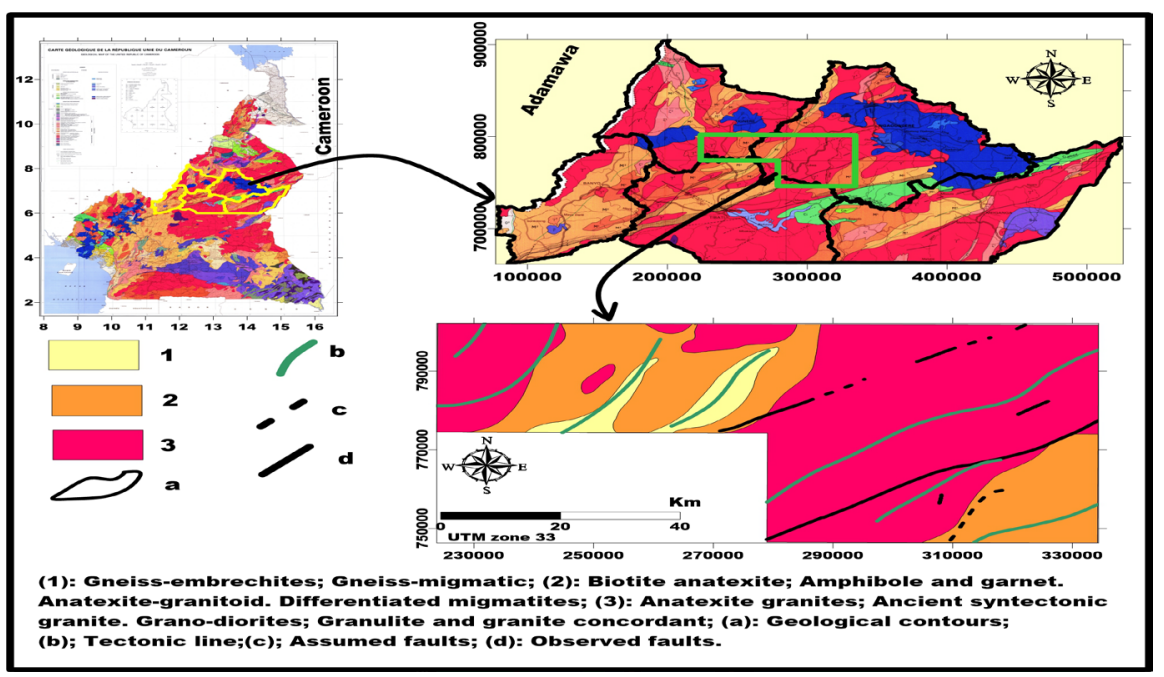

Figure 1. Geological map of the study area (Reproduced and modified after Guiraudie \& Lasserre [17]). 
This plateau has an altitude of $1100 \mathrm{~m}$ above sea level, with large basaltic flows accompanied by trachytes and trachyphonolites [3] [11] [12].

A thematic map of the mineral resources of Cameroon published in 2001 by the Ministry of Mines, Water and Energy (MINMEE) shows several indices of mineralization (Gold, Aluminum, Germanium, Tin, Thermal springs) in the studied area (Figure 2). Part of the bauxite plateau of MinimMartap is perfectly superimposed on the Aluminum indices found in the south of the studied area (Figure 2).

\section{Materials and Methods}

\subsection{Origin of Aeromagnetic Data}

The data set used in the present study was obtained an aeromagnetic survey covering some parts of the Cameroon territory [21]. This aeromagnetic survey was conducted in 1970 by Survair Limited (Ottawa) as part of a co-operative agreement between the Canadian and the Cameroon government. The flying height was 235 Meters, flight lines had a N135 ${ }^{\circ} \mathrm{E}$ direction with 750 meters interlines space and the recording sensitivity of the magnetometer used was than 0.5 $\mathrm{nT}$ [21]. After correction of the measurements due to the temporary variation of the magnetic field, the final report of Paterson et al. [21] was accompanied by magnetic maps. The digitization of these maps made it possible to have a data base of 1,396,268 measuring points for the entire studied area $\left(4647 \mathrm{Km}^{2}\right)$. The total magnetic intensity (TMI) anomaly was deduced by subtracting the theoretical geomagnetic field or IGRF (International Geomagnetic Reference Field) at each station. This map was (Figure 3 ) made using a sampling rate of 0.01 degree $(1.1 \mathrm{~km})$.

Indeed, unlike the gravitational attraction field, which is vertical and always directed downwards, the magnetization field vector and the inductive field vector are generally inclined, thus causing an asymmetry in the shape of the anomalies. To correct this error, a reduction to the pole or the equator is often applied to the basic data. In the case of this study, given that Cameroon is moving from

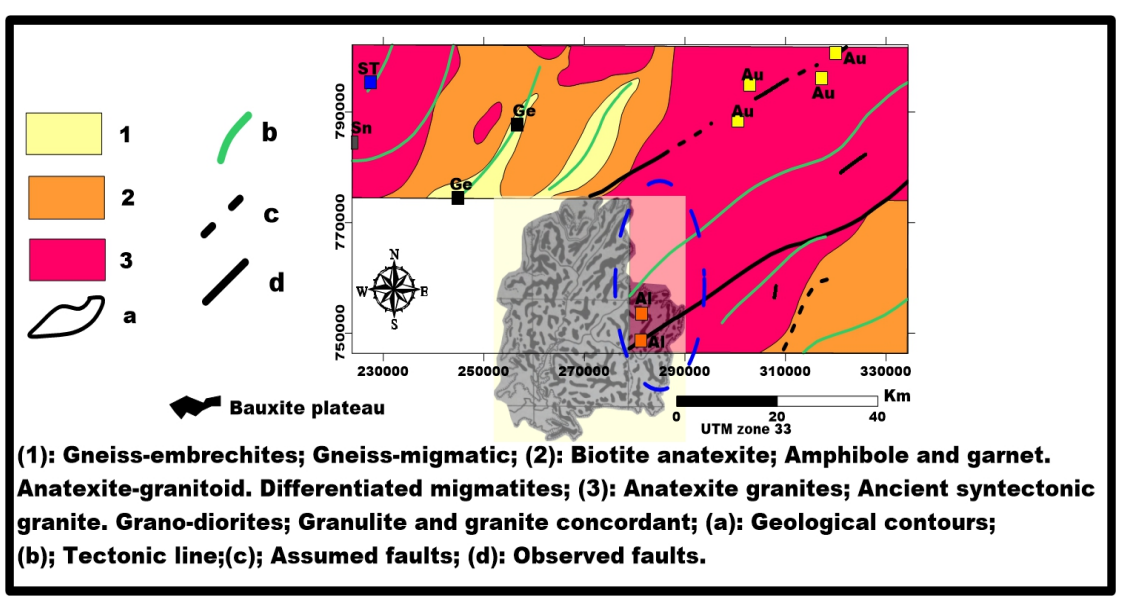

Figure 2. Mineral Resource Map of the Studied Area (MINMEE, 2001). 


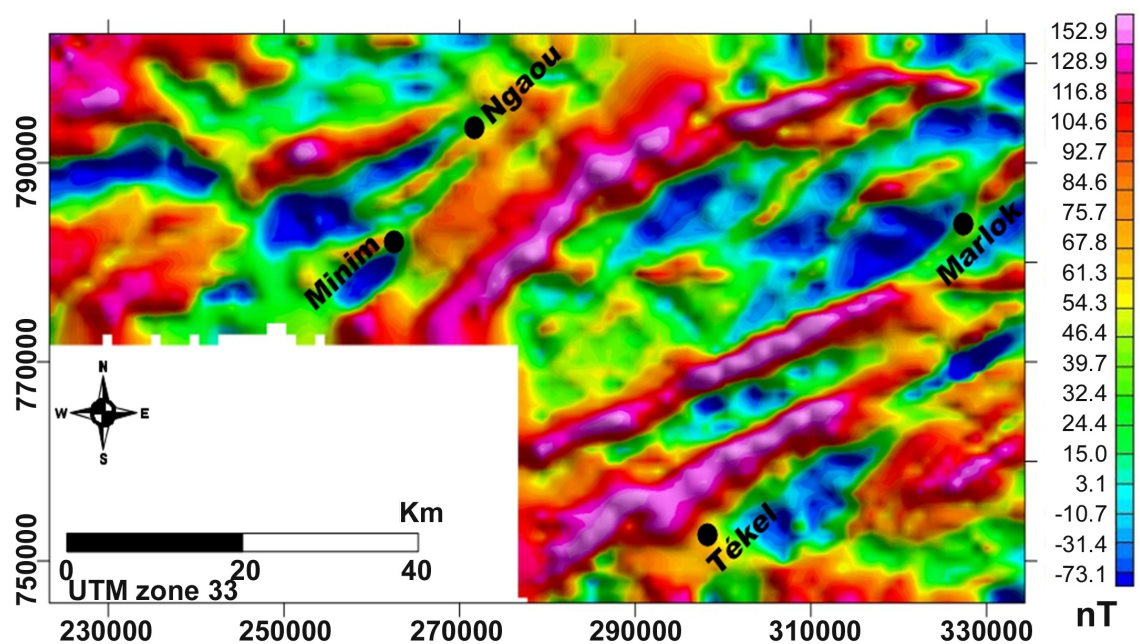

Figure 3. Total magnetic intensity anomaly map of the study area (TMI).

low-latitude areas $\left(-15^{\circ}\right.$ and $\left.15^{\circ}\right)$, it was necessary to calculate the reduction at the equator in order to bring anomalies back into line with the structures which generates them, since any analysis of anomalies is somewhat influenced by the inclination of the magnetic field and that of the magnetization direction of the magnetic fields sources. This reduction filter is calculated by choosing a point located at the center of the magnetic anomaly map ( $13.028^{\circ}$ East and $7.04^{\circ}$ North) with inclination and declination values from the model of the normal or theoretical field of the magnetic anomaly map IGRF at January 1, 1970. From the TMI anomaly map (Figure 3), the one reduced to the equator (Figure 4) was carried out from the Magma module of the Geosoft Oasis Montaj software.

\subsection{Methods}

A set of methods were used in the processing of the present aeromagnetic data. These included the gradient method, the analytic signal, the Euler deconvolution method, and modelling methods.

\subsubsection{Horizontal Gradient}

The horizontal gradient method is in many ways the simplest approach to estimate contact locations of the bodies at depths. The biggest advantage of the horizontal gradient method is its low sensitivity to the noise in the data because it only requires calculations of the two first-order horizontal derivatives of the field [22] [23]. If $M$ is the magnetic field then the horizontal gradient magnitude (HGM) is given by Cordell et al. [24] [25]:

$$
\operatorname{HGM}(x, y)=\sqrt{\left(\frac{\partial M}{\partial x}\right)^{2}+\left(\frac{\partial M}{\partial y}\right)^{2}}
$$

This function gives a peak anomaly above magnetic contacts under the following assumptions [22]: 1) the regional magnetic field is vertical, 2) the magnetizations are vertical, 3) the contacts are vertical, 4) the contacts are isolated, and 


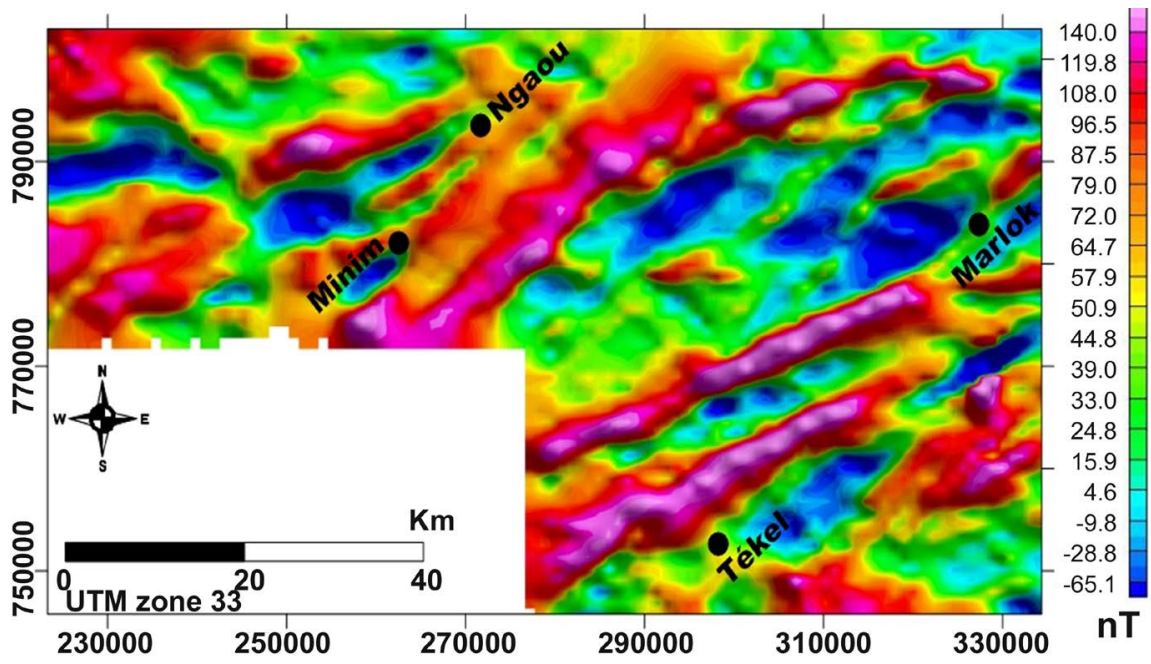

Figure 4. Total magnetic intensity map reduced to the equator (TMI-RTE).

5) the sources are thick. Violations of the first four assumptions can lead to shifts of the peaks away from the contacts. Violations of the fifth assumption can lead to secondary peaks parallel to the contacts.

\subsubsection{Analytic Signal}

Absolute analytic signal magnitude (ASM) according to [26] [27] [28] can be defined as the square root of the squared sum of the vertical and horizontal derivatives of the magnetic field as follows:

$$
\|\operatorname{ASM}(x, y)\|=\sqrt{\left(\frac{\partial f(x, y)}{\partial x}\right)^{2}+\left(\frac{\partial f(x, y)}{\partial y}\right)^{2}+\left(\frac{\partial f(x, y)}{\partial z}\right)^{2}}
$$

The advantage of this method of magnetic data enhancement is that its amplitude function is always positive and does not need any assumption of the direction of body magnetization [29]. In a manner identical to that used in the horizontal gradient method, peaks in the analytic signal amplitude are located. The maxima of the analytic signal can be used to detect the structures responsible for the observed magnetic anomalies over the studied area.

\subsubsection{D Euler Deconvolution}

Depth estimation by Euler deconvolution technique was used for delineating geologic contacts. This technique provides automatic estimates of source location and depth. Therefore, Euler deconvolution is both a boundary finder and depth estimation method. Euler deconvolution is commonly employed in magnetic interpretation because it requires only a little prior knowledge about the magnetic source geometry, and more importantly, it requires no information about the magnetization vector [30] [31]. Euler deconvolution is based on solving Euler's homogeneity Equation (3) [31]:

$$
\frac{\left(x-x_{o}\right) \partial M}{\partial x}+\frac{\left(y-y_{o}\right) \partial M}{\partial y}+\frac{\left(z-z_{o}\right) \partial M}{\partial z}=N(B-M)
$$


where $\mathrm{B}$ is the regional value of the total magnetic field and $\left(x_{0}, y_{0}, z_{0}\right)$ is the position of the magnetic source, which produces the total magnetic field $M$ measured at $(x, y, z) . N$ is so called structural index. For each position of the moving window, on over-estimated system of linear equations is solved for the position and depth of the sources [30] [31].

\subsection{Modelling Methods}

The 2.5D modeling shows a vertical section of the geological formations of the subsoil and the magnetic property (magnetic susceptibility) of each of the formations encountered. The objective of this modeling is to obtain a model calculated from an observed model of a magnetic field. All the programs use a $2.5 \mathrm{D}$ Talwani algorithm to calculate the magnetic field anomaly produced by the causative bodies [32] [33]. The profile direction is assumed to cut the bodies being modeled at $90^{\circ}$, the bodies themselves being represented by polygonal shapes of up to 50 sides. The profile bisects the bodies, which extend along strike an equal distance on each side. Although these assumptions may sound restrictive, in practice they do not cause difficulties most of the time.

The equation associated with this modeling is:

$$
\Delta B_{y^{\left(r_{0}\right)}}=-2 J j_{y} \sum\left(\tan ^{-1} \frac{u_{i+1}+Y}{w_{i} R_{i+1}}-\tan ^{-1} \frac{u_{i} Y}{w_{i} R_{i}}\right)
$$

where the profile is in the $x$ plane, $z$ is down and $y$ is orthogonal to both. $J$ is the magnetization of the body. $R_{i}=\sqrt{\left(u_{i}^{2}+w_{i}^{2}+Y^{2}\right)} ; r_{i+1}=\sqrt{\left(u_{i+1}^{2}+w_{i}^{2}\right)}$; $w_{i}=-\sin \varnothing_{i} x_{i}+\cos \varnothing_{i} x_{i+1}$ and $u_{i}=\cos \varnothing_{i} x_{i+1}+\sin \varnothing_{i} z_{i}$

\section{Results and Discussion}

\subsection{Residual Anomaly and Correlation with the Geology of the Area}

The TMI-RTE map (Figure 4) results from the superposition of short wavelength anomalies (local or residual anomalies) and long wavelength anomalies (regional anomalies). Since it was a question here of looking more specifically at the local anomalies of the studied area, a regional separation technique-residual so-called prolongation was applied to the TMI-RTE map.

Indeed, the extension consists in artificially moving the observation plane and calculating the field that one would observe in these new points from the data collected in the field. Extension can be up or down. But in this study, we will focus only on the upward extension. The latter makes it possible to pass the anomaly of the altitude $Z=0$ to an altitude $Z>0$. This operator acts as a low-pass electronic filter by attenuating the short wavelengths; highlighting the anomalies of deeper and deeper structures, depending on the altitude of the extension [9].

The upward extension, which is a powerful low-pass filter, is used here to determine the regional; however, this method also has a handicap that lies in the difficulty in determining the appropriate extension altitude in order to have the best approach to the regional. In the case of this study, we adopted the Zeng [34] 
method which is a compromise between upward extension and polynomial smoothing. It consists in evaluating the height $\mathrm{H}$ beyond which the magnetic anomalies extended upwards remain similar. Thus, several upward extensions of the TMI-RTE map are calculated at increasing altitudes of $500 \mathrm{~m}$ to $6000 \mathrm{~m}$. For each extended map, the number of extrema (points where the gradient is zero) $\mathrm{N}$ is counted. The height $\mathrm{H}_{\max }$ retained is such that the number of extrema of the extended map at heights greater than $\mathrm{H}_{\max }$ remains approximately constant. In this case, it would correspond to $5000 \mathrm{~m}$ or $5 \mathrm{Km}$.

The map of regional anomalies thus obtained is subtracted from the TMI-RTE map, which made it possible to obtain the residual anomaly map which is a map freed from the influence of the very deep structures (Figure 5).

Reduced residual map at equator shows smoothing and stretching of anomalies on the horizontal plane. It also shows the magnitudes of anomalies that vary between -100 and $80 \mathrm{nT}$. The superimposition (Figure 6) of the residual Map reduced to the equator (Figure 5) to the geological map (Figure 1) allows the following correlations, based on geological assumptions and analysis made on the map residual reduced to the equator.

In the South-East of the studied area, the identified ENE-WSW positive anomalies are perfectly superposed on the large fault (thick black line in Figure 1) located in the South-East of the geological map. This direction is therefore sub-parallel to one of the two major tectonic directions of the studied area $\left(\mathrm{N} 70^{\circ} \mathrm{E}\right)$ corresponding to the major pan-African structures of North Cameroon. This direction is also sub-parallel to the WSW-ENE major mylonitic band which constitutes the Ngaoundere cliff or fault [2] [14] [15] [16].

At the center of the studied area, the NE-SW direction of the anomaly coincides with the tectonic line (thick green line in Figure 1) crossing the gneiss formation in the center of the geological map. It corresponds to the direction of the great fracturing that affected the Adamawa region and favoured the development of intense volcanic activity between the Tertiary and the Quaternary [2] [14] [15] [16].
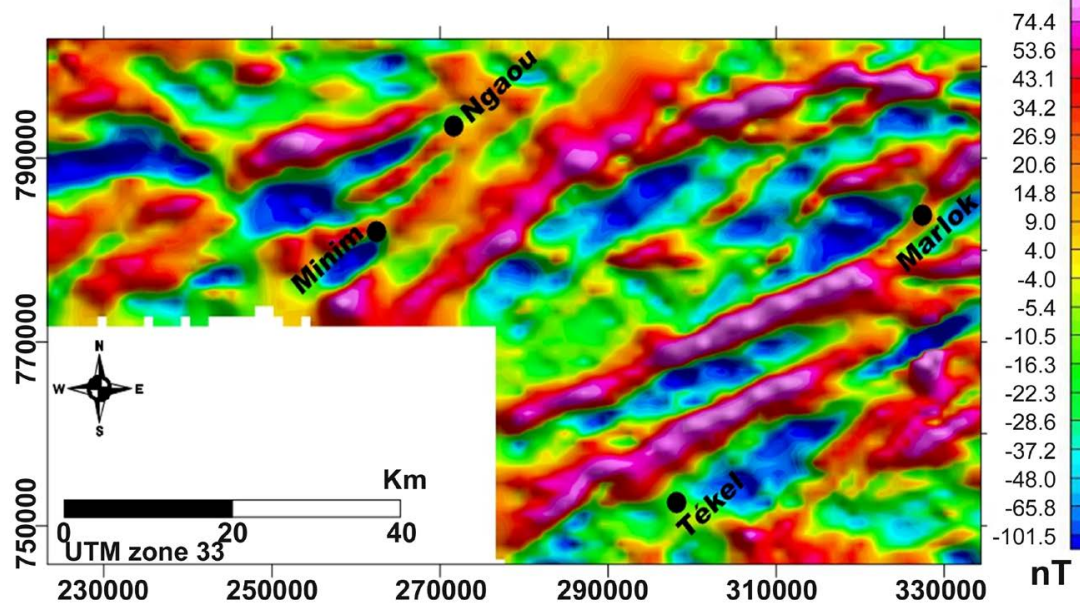

Figure 5. Reduced to the equator residual magnetic map. 


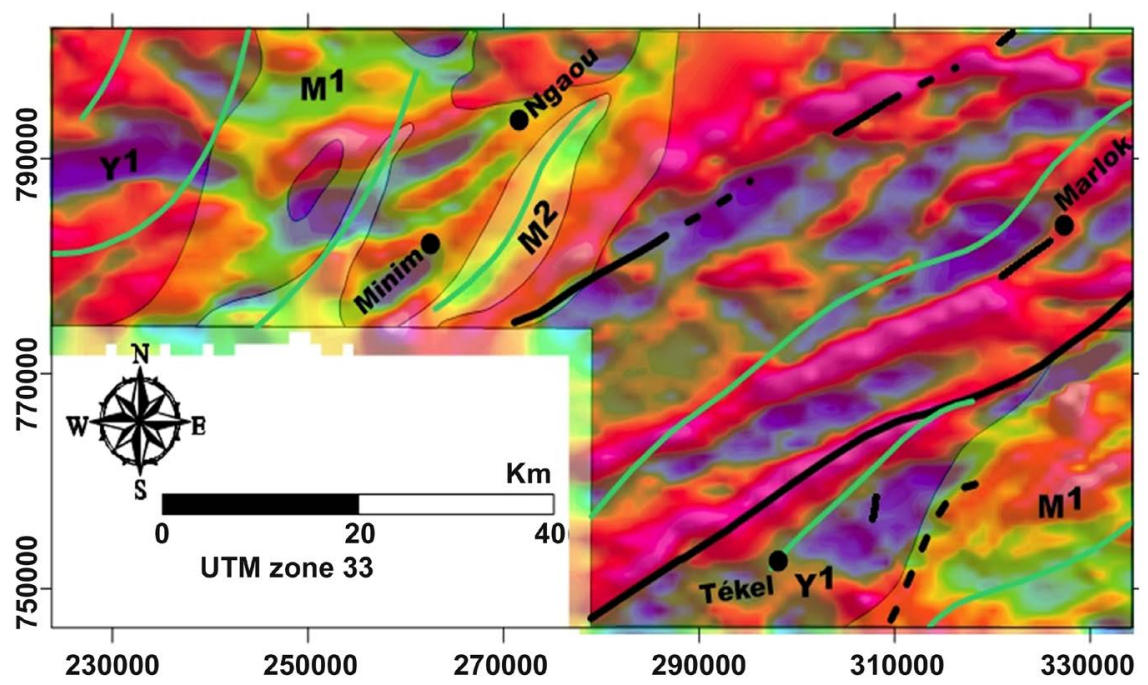

Figure 6. Superimposition of reduced to the equator residual magnetic and geological maps.

Based on previous correlations, the negative anomalies observed at the Marlok Zone Center (represented by the blue colour in Figure 5) appear to be trapped between two major ENEWSW faulting directions. We could therefore suspect here the presence of a graben. We also associated the observed negative anomalies with recent sedimentary deposits.

\subsection{Deep Faults and Contacts}

\subsubsection{Analysis of the Results of the Horizontal Gradient}

The horizontal gradient is an excellent way to locate geological contacts in the subsoil, including faults by determining their alignments, dips, and degree of importance [35] [36] (Khattach et al., 2004, 2006). Figure 7 represents the map of the Horizontal gradient magnitude (HGM) of the residual anomaly reduced to the equator. This map shows anomalies associated with continuous geological contacts and straighter than those observed on the residual anomaly map. It shows the major directions ENE-WSW and NE-SW. These anomalies correspond to magnetic contact zones with very large susceptibility differences associated with hidden faults. On this map, there are two main categories of contacts:

$>$ The most rectilinear contacts and strong intensities are grouped in the center of the zone between Minim and Tékel for several kilometers and characterize the signature of the faults in the covers.

- Contacts of circular to sub-circular shapes with high intensities are much more grouped north-west of Minim and also discontinuously in other areas of the map. These contacts characterize the limits of the intrusive bodies (dikes or veins of magmatic rock forming a depression).

To highlight the geological contacts associated with faults or fractures on the map of the Horizontal gradient magnitude (HGM), the map of the local maxima of the magnitude of the horizontal gradient of the residual anomaly (Figure 8) has been established. On this map, we observe a structural complexity marked 


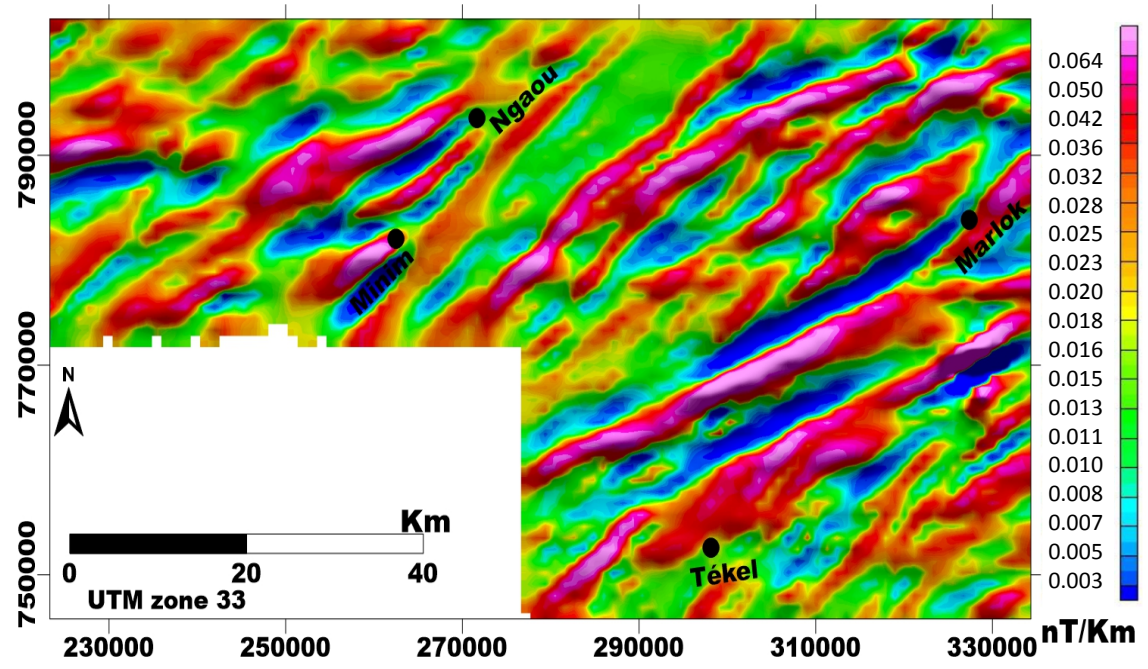

Figure 7. Horizontal gradient magnitude (HGM) map.

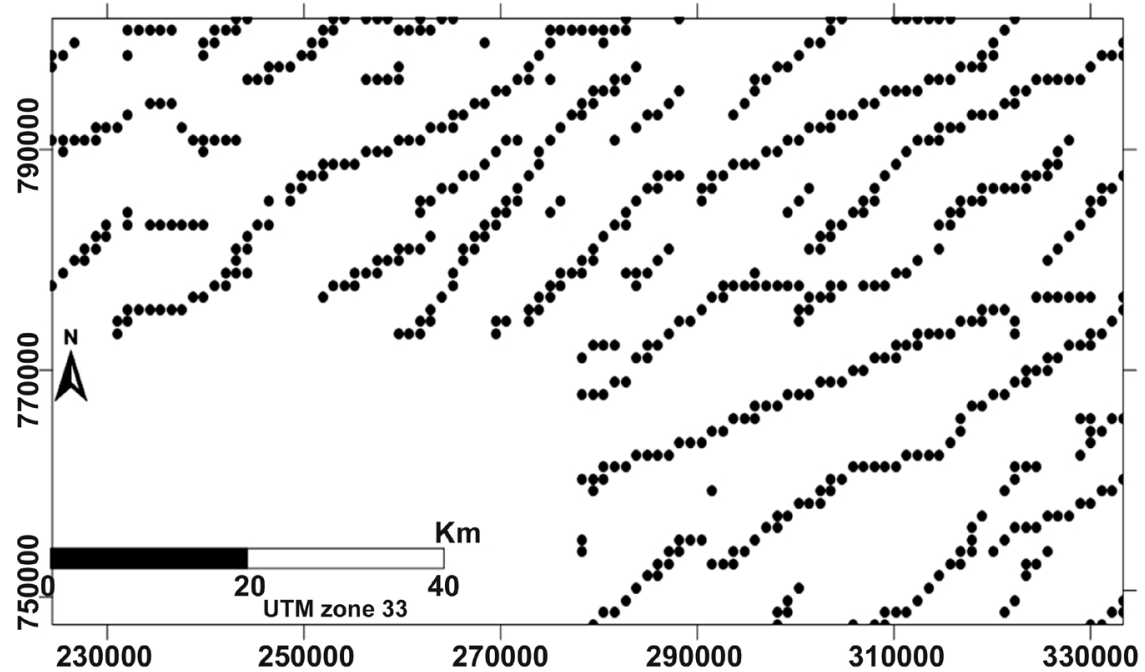

Figure 8. Maxima of the horizontal gradient magnitude.

by the irregular distribution of maxima associated with faults in the basement. In the center of this map, the configuration of ENE-WSW direction maxima suggests the presence of significant structural deformation in the base.

\subsubsection{Analysis of the Results of the Analytic Signal}

In order to better understand the relatively deep geological structures, the method of Analytical signal (AS) has been applied to the map of the residual anomaly. The map obtained (Figure 9) shows that the linear contacts corresponding to the faults are always grouped in the center (between Minim and Tékel) as well, the contacts of circular or intrusive forms clearly visible on this map, are much more grouped in the North frame West of Minim.

Horizontal gradient magnitude (HGM), the map of the local maxima of the analytical signal (Figure 10) has been established. It also shows the presence of structural deformation ENE-WSW in the center of the region. Three families of 


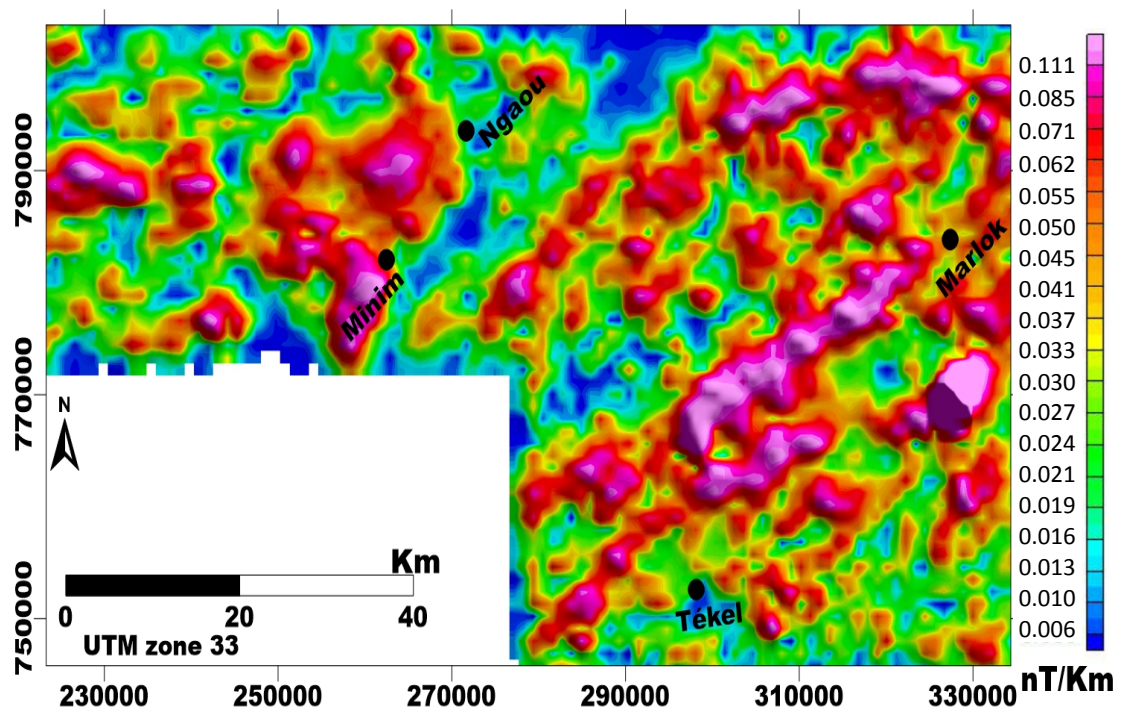

Figure 9. Analytic signal magnitude (AS) map.

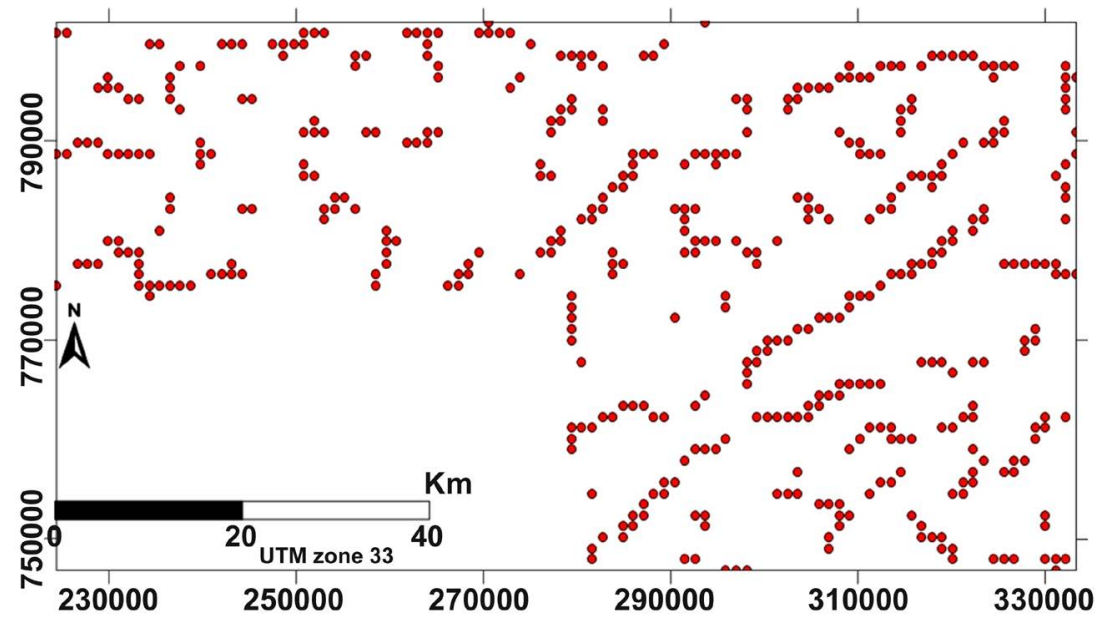

Figure 10. Maxima of the Analytic signal magnitude.

contacts are highlighted on this map namely the contacts: NE-SW; ENE-WSW and $\mathrm{E}-\mathrm{W}$.

HGM and AS association is very important in this study for the final interpretation of the geological contacts (Figure 11). The interpretation of the result of the superimposition of the maxima (Figure 12) of these two methods is based on three criteria (the method of Blakely and Simpson) [37]:

$>$ When the maxima of the horizontal gradient are isolated on the map of the two superimposed methods, they represent the real contacts.

$>$ When the maxima of the analytical signal and the horizontal gradient are almost parallel and not coincidental, then those of the analytical signal represent the true contacts and those of the horizontal gradient indicate the direction of dip of these contacts.

When the maxima of the two methods are merged, then they materialize the vertical contacts. 


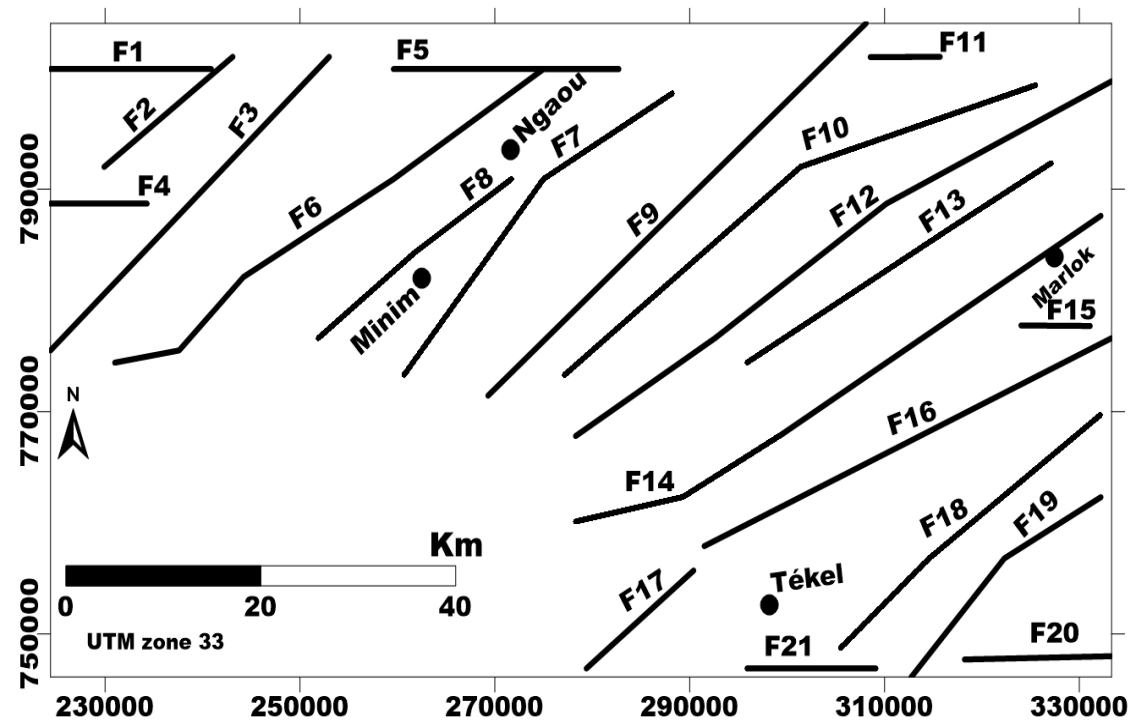

Figure 11. Map of deep faults in the study area.

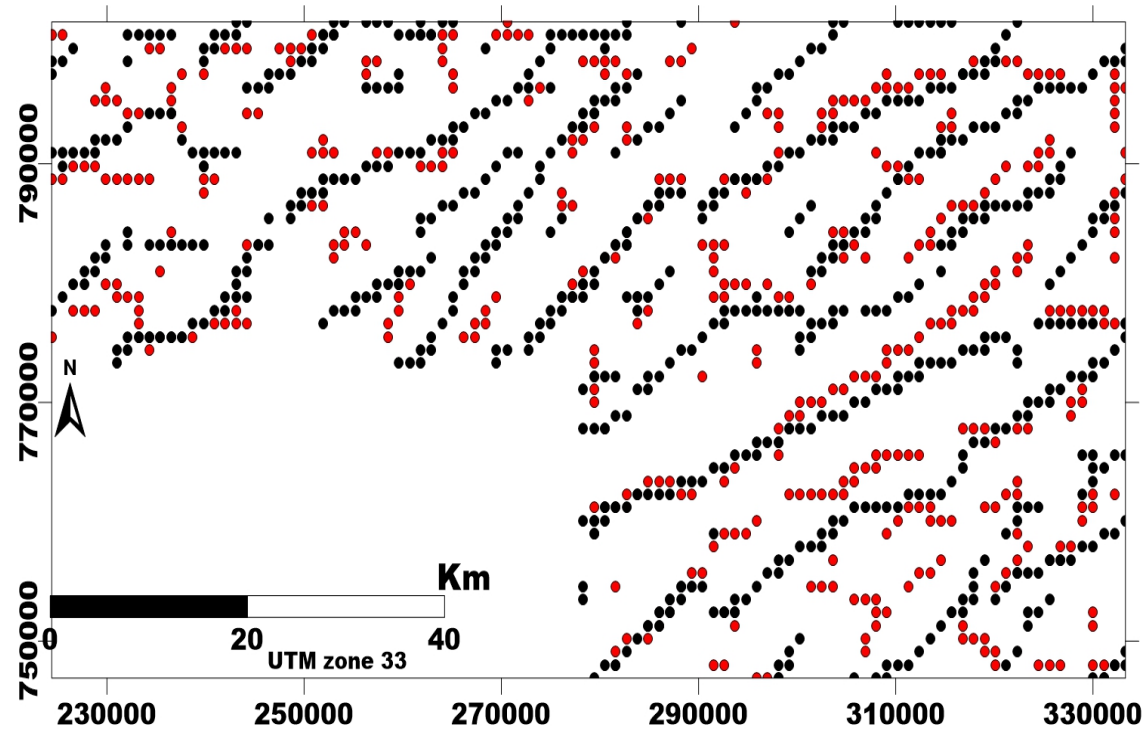

Figure 12. Map of maxima composed of horizontal gradient (black) and analytical signal (red).

The rosette of fracture directions (Figure 13) obtained from the interpretive map of deep faults (Figure 11) shows three major families of fracturing namely: E-W, NE-SW, ENE-WSW.

\subsubsection{Contributions of the 3-D Euler Deconvolution}

The inversion by the Euler method was carried out using the Euler 3D calculation program incorporated in Geosoft oasis montaj. This is a very effective method that can locate the magnetic contacts in the horizontal plane and their different depths. This is the reason why it has been applied to the residual map. The application of the Euler deconvolution requires the knowledge of three parameters which are: the structural index $\mathrm{N}$, the dimensions of the filter window $\mathrm{W}$ 


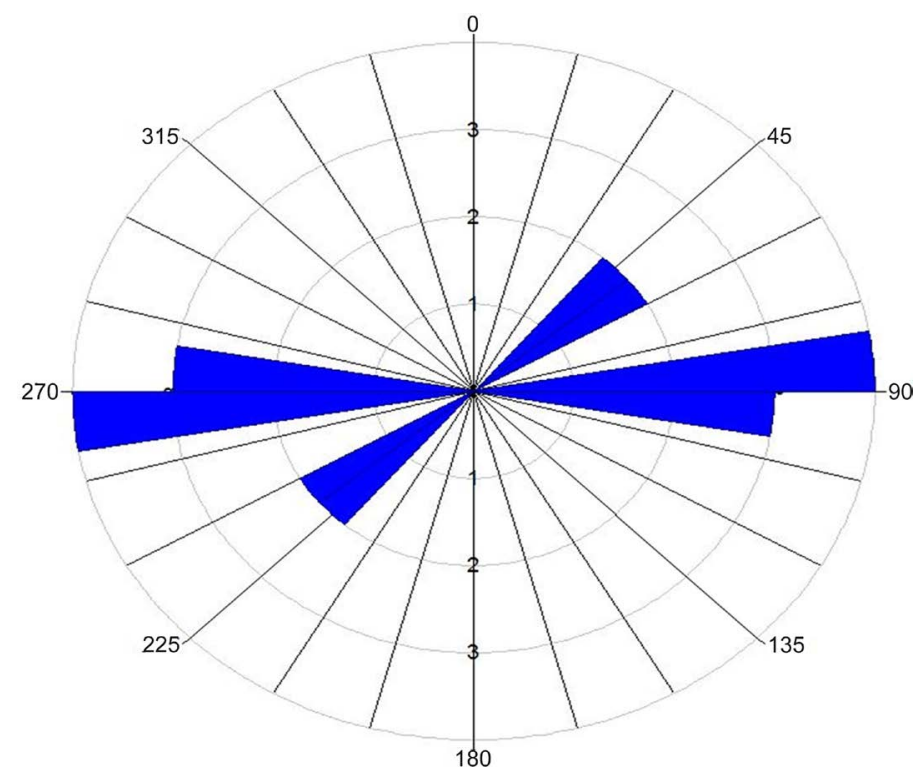

Figure 13. The rosette of fracture directions.

and the tolerance $\mathrm{Z}$. Since the objective was to highlight the solutions related to geological contacts, in this study, several tests were carried out by varying various $\mathrm{N}, \mathrm{W}$ and $\mathrm{Z}$ parameters. All these made it possible to notice that the best results or groupings of the Euler solutions are obtained for a window size equal to 3 , a selection criterion of the solutions which is the tolerance of $12 \%$ and a structural index of 0 .

Figure 14 shows the distribution of Euler's solutions for the parameters of the selected geological contacts. On this map, the structures are identified in a range of depths ranging from about 600 to $2000 \mathrm{~m}$.

The superimposition of this map (Figure 14) to that of the (Figure 15) provides an estimate of the depths of the faults obtained based on the alignment of the solutions at the levels of the different contacts (Table 1).

\subsubsection{Correlation between Magnetic Anomalies, Geological Structures and Mineralization}

By superimposing on the map of residual anomalies reduced to the equator the mining index maps, and deep faults in the studied area (Figure 16), several interpretations can be made:

Some clues $(\mathrm{Au}, \mathrm{Sn}, \mathrm{Ge})$ are found at the edges of rivers and these are related to geological structures.

Gold $(\mathrm{Au})$ clues found in the area appear to be superimposed on strong NE-SW magnetic direction signals recorded north of Marlok.

$>$ To the west of Tékel, the Aluminum (Al) index, as well as the portion of the bauxite plateau of Minim-Martap (represented by the blue circle in Figure 16 found in the study area, seem to coincide with the two high magnetic signals that have a direction similar to that of the mylonitic cliff of Ngaoundere namely the direction ENE-WSW. This proves that these anomalies could extend beyond the studied area in the same direction. 


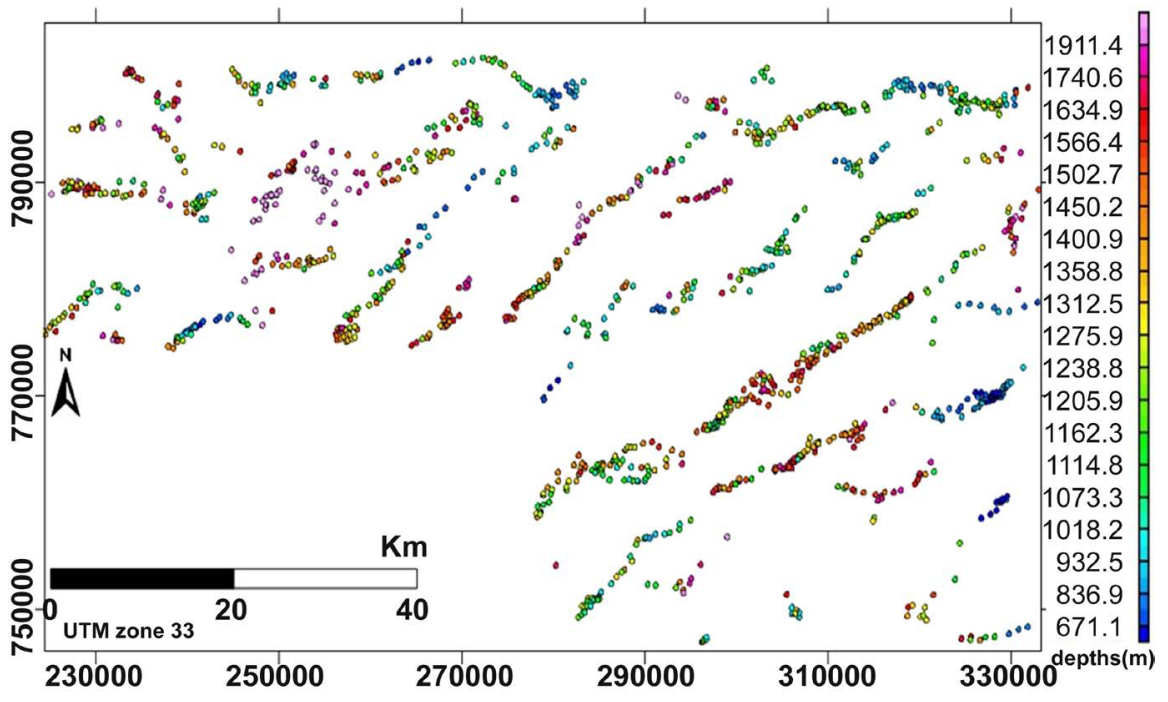

Figure 14. Euler solution map for a $N=0, W=3$ and $Z=12 \%$.

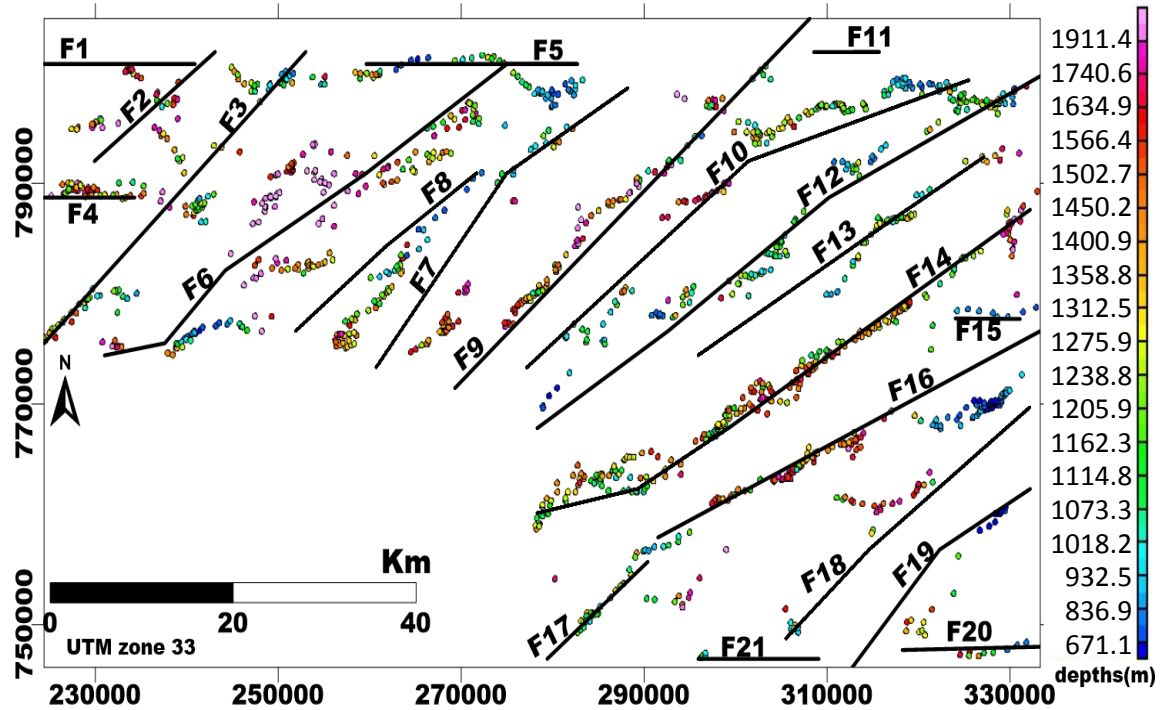

Figure 15. Map of deep faults in the study area.

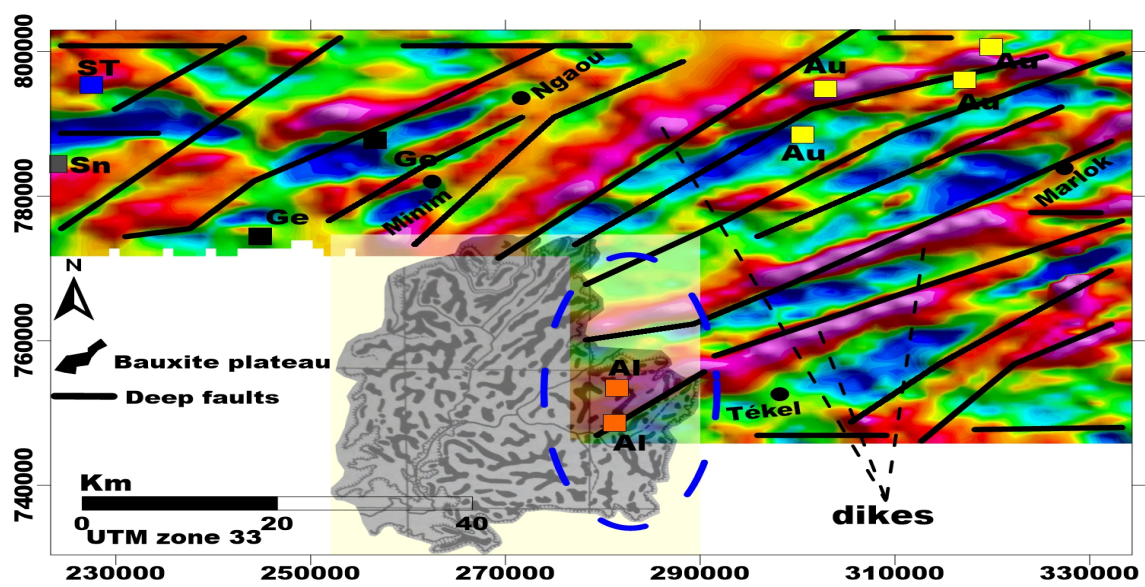

Figure 16. Relationship between anomalies and mining index. 
Table 1. Characteristics of deep faults.

\begin{tabular}{cccccc}
\hline Faults & Dips & Approximate depths $(\mathrm{m})$ & Faults & Dips & Approximate depths (m) \\
\hline F1 & Vertical & $1200-1500$ & F12 & Vertical & $900-1000$ \\
F2 & Vertical & $1100-1200$ & F13 & SE & $1000-1300$ \\
F3 & Vertical & $1000-1300$ & F14 & Vertical & $1000-1500$ \\
F4 & N-S & $1000-1500$ & F15 & S & $650-850$ \\
F5 & Vertical & $800-1000$ & F16 & Vertical & $1200-1700$ \\
F6 & Vertical & $1500-1700$ & F17 & Vertical & $950-1100$ \\
F7 & NW & $1200-1500$ & F18 & SE & $900-1000$ \\
F8 & SE & $600-700$ & F19 & SE & $600-680$ \\
F9 & Vertical & $900-1000$ & F20 & N-S & $700-1000$ \\
F10 & NW & $1000-1500$ & F21 & N-S & $800-900$ \\
F11 & N-S & Unknown & & & \\
\hline
\end{tabular}

The other elements namely tin (Sn) and Germanium (Ge) appear to be related to recent sedimentary formations outcropping in the north-western part of the studied area (North-West of Minim).

In summary, the reduction of magnetic data to the equator yielded a map that reflects the degree of concentration of magnetic minerals at the studied area scale's. This map has been superimposed on that of the geology of the studied area. Its examination makes it possible to realize that the highlighted lineaments represent, for the most part, sub-meridian magnetic structures, offset by transverse faults with dextral plays.

The very elongated shape of most anomalies represents the magnetic signature of also elongated sources that may correspond to veins or other lenses. However, the very high amplitude of the magmatic signals of these anomalies makes it possible to exclude the hypothesis of the quartz, which cannot present such a signal. The elongated shape of these anomalies as well as their high amplitude is therefore suitable for bodies meeting these criteria, namely: the dikes. The dikes are actually veins of magmatic rocks that have infiltrated the various fractures of the country. It is therefore an intrusive phenomenon in an open crack. This phenomenon is very visible on the residual map of the studied area (Figure 16).

Taking into account the faults obtained, the dikes observed on the residual map as well as the mineralization index, and integrating them with the map of Figure 1, one obtains a geological map Figure 17 much more informed which actually shows that the mineralization of the zone of studied are actually associated with the zones of geological structures or zones of faults.

\subsection{Modelling}

The 2.5D modelling was performed on two magnetic profiles (P1 and P2) of NNW-SSE directions. These profiles plotted on the residual map reduced to the 


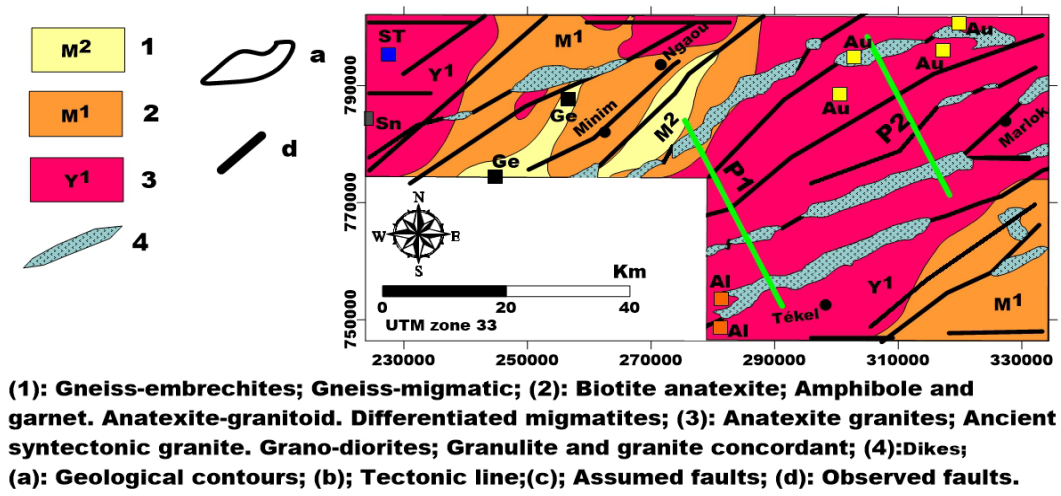

Figure 17. Interpretive geological map.

Equator (Figure 5) are $35 \mathrm{~km}$ long for $\mathrm{P} 1$ and $30 \mathrm{~km}$ long for P2 respectively. They transversely cross the major anomalies of the studied area that are fairly representative (major anomalies) of all the anomalies of the entire studied area.

Previous interpretations show that the mineralization indices are associated with the geological contacts or structures of the sector and in particular with the dikes (Paragraph 4.2.4) which are folded fractures by newcomers of magmatic fluids within a host. The objective of this modeling was therefore to highlight these dikes in a vertical section, thus giving their geometry, their approximate depth, as well as the other associated geologies.

The association of the horizontal gradient method with that of the analytical signal and the analysis made on other magmatic maps shows that the dikes of the studied area are associated with vertical faults (Table 1). The deconvolution of Euler made it possible to constrain the depth of modeling to $2 \mathrm{~km}$ below the topographic level. The formations of the model were delimited by using two types of analysis: magnetic relief analysis and geological analysis traversed by the profiles (Figure 17), thus by synchronizing or mosaicking several data windows. All these analysis made it possible to establish the limits of modeling.

Figure 18 and Figure 19 respectively represent the models of profiles P1 and P2. The P1 model shows four (04) formations: a formation of cover or sediments, gneiss, granite and dikes. For this model, from NNW to SSE, three (03) dikes intrusions associated with vertical contacts are observed at depths between about 300 and 1880 meters below the topographic level.

For the $\mathrm{P} 2$ model, in addition to sediment, we have granite and dikes. From NNW to SSE, two (02) dikes intrusions also occurred associated with vertical contacts at depths between 450 and 1400 meters below the topographic level.

The apparent magmatic susceptibility of the dikes, obtained from modeling (S $=0.1278)$, is similar to that of diorite $(S=0.13)$ according to the classification of rocks and minerals according to their magmatic susceptibilities of Hunt et al. [38].

\section{Conclusion}

The treatment and interpretation of the aeromagnetic data made it possible to 


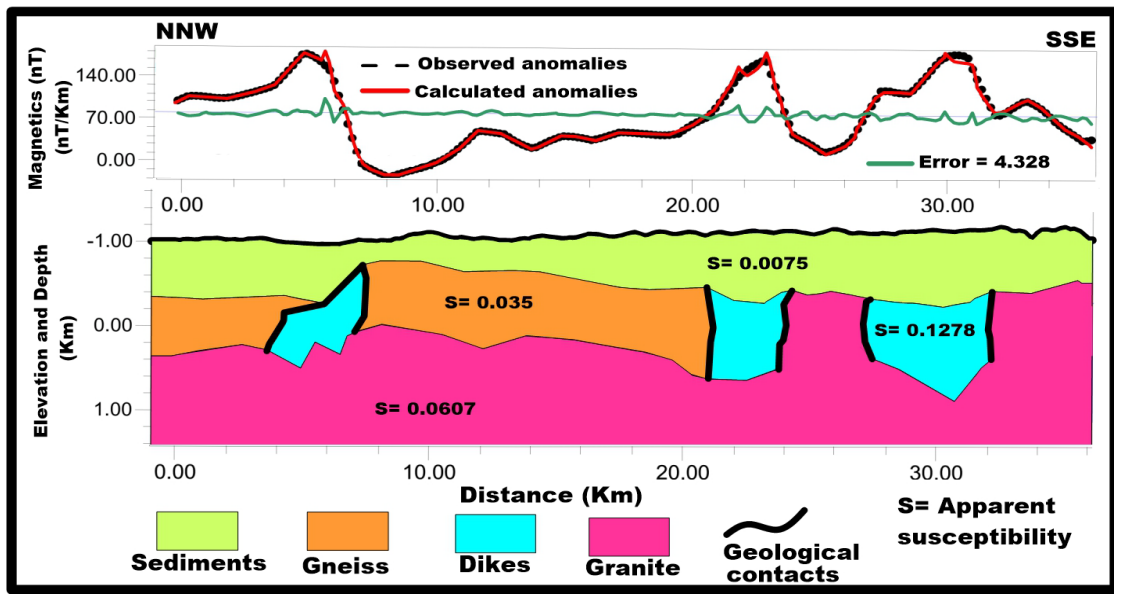

Figure 18. 2.5D Model of Profile 1.

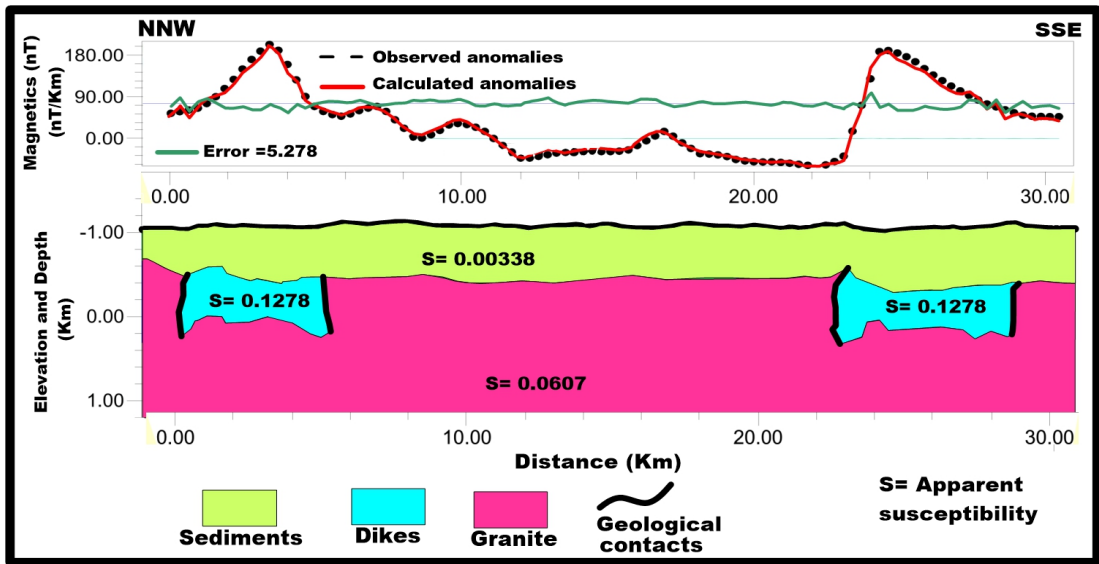

Figure 19. 2.5D Model of Profile 2.

know the structure of the subsoil of the studied area from the analysis of the magnetic surface signals. Indeed, the combination of analytical methods (HG, AS, ED) has made it possible to highlight the deep faults and their approximate depths. The major directions of these faults namely ENE-WSW $\left(\mathrm{N}^{\circ} 0^{\circ} \mathrm{E}\right)$ and NE-SW $\left(\mathrm{N} 45^{\circ} \mathrm{E}\right)$ coincide with those found by [6] [9] in their respective researched work. The combinatorial analysis of different magmatic maps shows dikes associated with vertical faults in the studied area. The geological interpretative map obtained by combining the basic geologic data, deep faults and identified dikes shows that the mineralization indices of the study area are in fault zones. Therefore, the sources of these indices could be associated with the geological structures (dikes in particular) of the studied area. The 2.5D modelling of two magnetic profiles has been done with the aim of approaching the geometry and depth of the dikes sector, which are potential sources of mineralization here. The results of the modeling thus show dikes associated with vertical contacts and located at extreme depths between 300 and 1880 meters below the topographic level. The apparent magmatic susceptibility of the dikes, obtained from modelling $(S=0.1278)$, is similar to that of diorite $(S=0.13)$ according to the classifi- 
cation of rocks and minerals according to their magmatic susceptibilities of Hunt et al. [38]. All the results thus obtained make it possible to have more advanced knowledge of the geological structures and mineralization of the studied area for possible mineral exploration.

\section{Conflicts of Interest}

The authors declare that there is no conflict of interest regarding the publication of this paper.

\section{References}

[1] Belinga, E. (1972) The Alteration of Basaltic Rocks and the Process of Bauxitization in Adamawa (Cameroon). Thesis Doc., State University, Paris, 571.

[2] Dumont, J.F. (1987) Structural Study of the North and South Borders of the Adamawa Plateau: Influence of the Atlantic Context. Geodynamics, 1, 9-13.

[3] Ngounouno, I. (1998) Petrology and Geodynamic Framework of the Cenozoic Magmatism of the Cameroon Line. In: Vicat, J.P. and Bilong, P., Eds., Geoscience in Cameroon, Collection GEOCAM, Vol. 1, 169-184.

[4] Poudjom-Djomani, Y.H., Diament, M. and Albouy, Y. (1992) Mechanical Behaviour of the Lithosphere beneath the Adamawa Uplift (Cameroon, West Africa) Based on Gravity Data. Journal of Africa Earth Sciences, 15, 81-90. https://doi.org/10.1016/0899-5362(92)90009-2

[5] Poudjom-Djomani, Y.H. (1993) Contribution of Gravimetry to the Study of the Continental Lithosphere and Geodynamic Implications. Study of an Intraplaque Bombing: The Adamaoua Massif (Cameroon). PhD Thesis, University South of Paris, Paris, 229.

[6] Poudjom-Djomani, Y.H., Nnange, J.M., Diament, M., Ebinger, C.J. and Fairhead, J.D. (1995) Effective Elastic Thickness and Crustal Thickness Variations in West Central Africa Inferred from Gravity Data. Journal of Geophysical Research, 100, 47-70.

[7] Poudjom-Djomani, Y.H., Diament, M. and Wilson, M. (1997) Lithospheric Structures across the Adamawa Plateau (Cameroon) from Gravity Studies. Tectonophysics, 273, 317-327. https://doi.org/10.1016/S0040-1951(96)00280-6

[8] Noutchogwe, T.C., Tabod, C.T. and Manguelle-Dicoum, E. (2006) A Gravity Study of the Crust Beneath the Adamawa Fault Zone, West Central Africa. Journal of geophysics and Engineering, 3, 82-89. https://doi.org/10.1088/1742-2132/3/1/009

[9] Noutchogwe, T.C. (2010) Geophysical Investigation in the Adamawa Region by Gravimetric and Magnetic Methods: Structural and Hydrogeological Implications. PhD Thesis, University of Yaoundé I, Yaoundé, 146.

[10] Marechal, A. and Vincent, P.R. (1971) The Cretaceous Pit of South Adamawa (Cameroon). ORSTOM Book, Geological Series, 3, 67-83.

[11] Temdjim, R. (1986) Volcanism of the Region of Ngaoundere (Adamawa-Cameroon). Volcanic and Petrographic Study. Thesis, 3rd Cycle, University Clermont Ferrand, France, 185.

[12] Temdjim, R. (2006) Contribution to the Knowledge of the Upper Mantle of Cameroon through the Study of Ultrabasic and Basic Enclaves Ascended by the Volcanoes of Youkou (Adamawa) and Nyos (Cameroon Line). Thesis State, University of Yaounde I, 346. 
[13] Ngounouno, I., Moreau, C., Deruelle, B., Demaiffe, D. and Montigny, R. (2001) Petrology of the Subsaturated Alkaline Complex of Koukoumi (North of Cameroon). Bulletin de la Société Géologique de France, 172, 675-686. https://doi.org/10.2113/172.6.675

[14] Lassere, M. (1961) Geological Map of Recognition at a Scale of 1: 500,000, Cameroon Territory, Ngaoundere East. Dir. Mines Geol. Cameroon.

[15] Koch, P. (1953) Geological Map of Cameroon. Banyo Clipping, with Explanatory Note.

[16] Cornacchia, M. and Dars, R. (1983) A Major Structural Feature of the African Continent: The Central African Lineaments from Cameroon to the Gulf of Aden. Bull. COC.Geol. France, 25, 101-109.

[17] Lasserre, M. (1961) Geological Map of Reconnaissance at Scale 1/500000, Territory of Cameroon, Ngaoundere-East. Dir, Mines Geol Cameroon, Yaounde, Camerooùn.

[18] EnoBelinga (1984) Geology of Cameroon. Yaounde University, Yaounde, 308.

[19] Toteu, S.F., Van Schmus, W.R., Penaye, J. and Michard, A. (2001) New U-Pb and Sm-Nd Data from North-Central Cameroon and Its Bearing on the Pre-Pan African History of Central Africa. Precambrian Research, 108, 45-73. https://doi.org/10.1016/S0301-9268(00)00149-2

[20] Tchameni, R., Pouclet, A., Penaye, J., Ganwa, A.A. and Toteu, S.F. (2006) Petrography and Geochemistry of the Ngaoundere Pan-African Granitoids in Central Cameroon: Implications for Their Sources and Geological Setting. Journal of African Earth Sciences, 44, 511-529. https://doi.org/10.1016/j.jafrearsci.2005.11.017

[21] Paterson, Grant and Watson Ltd. (1976) Interpretation of an Aeromagnetic Survey Overpart of the United Republic of Cameroon. ACDI, Toronto, 190.

[22] Phillips, J.D. (1998) Processing and Interpretation of Aeromagnetic Data for the Santa Cruz Basin-Patahonia Mountains Area, South-Central Arizona. U.S. Geological Survey Open-File Report, Arizona, 2-98.

[23] Ngoh, J.D., Ndougsa-Mbarga, T., Assembe, S.P., Meying, A., Owono, O.U. and Tabod, T.C. (2017) Evidence of Structural Facts Inferred from Aeromagnetic Data Analysis over the Guider-Maroua Area (Northern Cameroon). International Journal of Geosciences, 8, 781-800. https://doi.org/10.4236/ijg.2017.86044

[24] Cordell, L. and Grauch, V.J.S. (1982) Mapping Basement Magnetization Zones from Aeromagnetic Data in the San Juan Basin, New Mexico. SEG Technical Program Expanded Abstracts, 246-247.

[25] Cordell, L. and Grauch, V.J.S. (1985) Mapping Basement Magnetization Zones from Aeromagnetic Data in the San Juan Basin, New Mexico. In: Hinze, W.J., Ed., The Utility of Regional Gravity and Magnetic Anomaly Maps, Society of Exploration Geophysicists, 181-197. https://doi.org/10.1190/1.0931830346.ch16

[26] Nabighian, M.N. (1972) The Analytic Signal of Two-Dimensional Magnetic Bodies with Polygonal Cross-Section: Its Properties and Use for Automated Anomaly Interpretation. Geophysics, 37, 507-517. https://doi.org/10.1190/1.1440276

[27] Roest, W.R., Verhoef, J. and Pilkigton, M. (1992) Magnetic Interpretation Using the 3-D Signal Analytic. Geophysics, 57, 116-125. https://doi.org/10.1190/1.1443174

[28] Macleod, I.N., Jones, K. and Dai, T.F. (1993) 3-D Analytic Signal in the Interpretation of Total Magnetic Field Data at Low Magnetic Latitudes. Exploration Geophysics, 24, 679-688. https://doi.org/10.1071/EG993679

[29] Jeng, Y., Lee, Y.L., Chen, C.Y. and Lin, M.J. (2003) Integrated Signal Enhancements in Magnetic Investigation in Archaeology. Journal of Applied Geophysics, 53, 
31-48. https://doi.org/10.1016/S0926-9851(03)00015-6

[30] Thompson, D.T. (1982) A New Technique for Making Computer-Assisted Depth Estimates from Magnetic Data. Geophysics, 47, 31-37. https://doi.org/10.1190/1.1441278

[31] Reid, A.B., Allsop, J.M., Granser, H., Millett, A.J. and Somerton, I.W. (1990) Magnetic Interpretation in Three Dimensions Using Euler Deconvolution. Geophysics, 55, 80-90. https://doi.org/10.1190/1.1442774

[32] Talwani, M. and Heirzler, J.R. (1964) Computation of Magnetic Anomalies Caused by Two-Dimensional Bodies with Application to the Mineral Industry Shape. Computers in the Mineral Industry, School of Earth Sciences, Stanford University, Stanford, 464-480.

[33] Grant, F.S. and West, G.F. (1965) Interpretation Theory in Applied Geophysics. McGraw-Hill, New York, 584.

[34] Zeng, H. (1989) Estimation of the Degree of Polynomial Fitted to Gravity Anomalies and Its Application. Geophysical Prospecting, 37, 959-973.

https://doi.org/10.1111/j.1365-2478.1989.tb02242.x

[35] Khattach, D., Keating, P., Mili, E.M., Chennouf, T., Andrieux, P. and Milhi, A. (2004) Contribution of Gravimetry to the Study of Basffa Structure (North-East Morocco): Hydrogeological Implications. Géoscience, 336, 1427-1432. https://doi.org/10.1016/j.crte.2004.09.012

[36] Khattach, D., Mraoui, H., Sbibih, D. and Chennouf, T. (2006) Multi-Scale Wavelet Analysis of Geological Contacts: Application to the Gravimetry of Nord-Eastern Morocco. Comptes Rendus Geoscience, 338, 521-526. https://doi.org/10.1016/j.crte.2006.03.002

[37] Blakely, R.J. and Simpson, R.W. (1986) Approximating Edges of Source Bodies from Magnetic or Gravity Anomalies. Geophysics, 51, 1494-1498. https://doi.org/10.1190/1.1442197

[38] Hunt, C.P., Moskowitz, B.M. and Banerjee, S.K. (1995) Magnetic Properties of Rocks and Minerals. In: Ahrens, T.J., Ed., Rock Physics \& Phase Relations: $A$ Handbook of Physical Constants, Vol. 3, American Geophysical Union, Washington DC, 189-204. https://doi.org/10.1029/RF003p0189 